Pacific Journal of Mathematic 


\title{
EXCEPTIONAL VALUES OF DIFFERENTIAL POLYNOMIALS
}

\author{
WILLIBALD DOERINGER
}

Let $f$ be a meromorphic non-rational function on $C$ and $Q[f], P[f]$ differential polynomials in $f$. Assuming that neither of them vanishes identically, functions of the form $f^{n} Q[f]+P[f], n \in N$, are shown not to have zero as a Picard or Borel exceptional value for sufficiently large $n$. Examples show that the estimates given for $n$ are optimal.

1. Introduction and results. In the present paper we concern ourselves with the value-distribution of differential polynomials. We make use or results from value-distribution theory and we use the common notations $m(r, f), N(r, f), T(r, f), \bar{N}(r, f), S(r, f)$ and so on. (cf., e.g., [3], [8]).

There has been quite a bit of investigation (cf. [2], [12]-[14]) of Picard values of certain expressions in a meromorphic function $f$ such as $f^{n} f^{\prime}$ or $f^{n}+f^{\prime}$. Our article extends some of the previous results, especially those of W. K. Hayman [4] and L. R. Sons [9]. Let $f$ be a meromorphic function-in this paper always in the sense of meromorphic in the whole plane-and let $n_{0}, n_{1}, \cdots, n_{k}$ be nonnegative entire numbers. We call

$$
M[f]=f^{n_{0}}\left(f^{\prime}\right)^{n_{1}} \cdots\left(f^{(k)}\right)^{n_{k}}
$$

a monomial in $f$ (cf. L. R. Sons [9]), $\gamma_{M}$ : $=n_{0}+n_{1}+\cdots+n_{k}$ its degree and $\Gamma_{M}$ : $=n_{0}+2 n_{1}+\cdots+(1+k) n_{k}$ its weight. Further, let $M_{1}[f], \cdots, M_{\ell}[f]$ denote monomials in $f$ and $a_{1}, \cdots, a_{\iota}$ meromorphic functions satisfying $T\left(r, a_{j}\right)=S(r, f), 1 \leqq j \leqq \ell$, then

$$
P[f]=a_{1} M_{1}[f]+\cdots+a_{\iota} M_{\iota}[f]
$$

is called a differential polynomial in $f$ of degree $\gamma_{P}:=\max _{j=1}^{\ell} \gamma_{M_{j}}$ and weight $\Gamma_{P}:=\max _{j=1}^{\ell} \Gamma_{M j}$ with coefficients $a_{j}$.

Using these definitions we can state the following results:

THEOREM 1. Let $f$ be a nonrational meromorphic function and let $Q[f], P[f]$ be differential polynomials in $f$ satisfying $Q[f](z) \not \equiv 0$, $P[f](z) \not \equiv 0$. Then zero is neither a Picard nor a Borel exceptional value of

$$
\Psi=f^{n} Q[f]+P[f]
$$

for any $n \in N$ with $n \geqq 3+\Gamma_{P}$ and in particular 


$$
\limsup _{r \rightarrow \infty} \frac{\bar{N}(r, 1 / \Psi)}{T(r, \Psi)}>0
$$

As an immediate consequence we get

COROLLARY 1. Let $f$ be a nonrational meromorphic function and

$$
\Psi=a f^{n_{0}} \cdots\left(f^{(k)}\right)^{n_{k}}
$$

a differential polynomial in $f, a \not \equiv 0$. Barring zero, $\Psi$ has no finite Picard or Borel exceptional values if only $n_{0} \geqq 3$ holds. And again

$$
\limsup _{r \rightarrow \infty} \frac{\bar{N}(r, 1 /(\Psi-c))}{T(r, \Psi)}>0
$$

holds for $c \in \boldsymbol{C} \backslash\{0\}$.

REMARK. L. R. Sons proved similar results in [9] for the case $a \equiv 1$ and $n_{0} \geqq 2$, however under the additional assumptions $n_{k} \geqq 1$ and $2^{k}\left(n_{0}+\sum_{i=0}^{k}(1+i) n_{i}\right)<\left(2^{k}+n_{0}-1\right)\left(\sum_{i=0}^{k}(1+i) n_{i}\right)$.

Theorem 1 can be sharpened by considering entire functions only.

THEOREM 2. Let $f$ be a transcendental entire function and let $Q[f], P[f]$ be differential polynomials in $f$, both not identically vanishing. Then

$$
\Psi=f^{n} Q[f]+P[f]
$$

does not assume zero as a Picard or Borel exceptional value for any $n \in N, n \geqq 2+\gamma_{P}$; and here also

$$
\limsup _{r \rightarrow \infty} \frac{\bar{N}(r, 1 / \Psi)}{T(r, \Psi)}>0
$$

holds for these $n$.

REMARK. Assuming $f$ to be entire Corollary 1 holds already for $n_{0} \geqq 2$.

We conclude by giving two examples which show that the estimates given for $n$ are optimal in the sense that they cannot be improved. First consider a nonconstant solution of the Riccati differential equation $w^{\prime}=-2(w-1)(w+1)$ which is a transcendental meromorphic function satisfying $w^{4}+w^{\prime} \neq 1$ (cf., e.g., [10], [11]); this settles Theorem 1.

Regarding Theorem 2 we choose an entire transcendental solution 
of the linear differential equation $w^{(j)}=-2 a c(w-c), j \in N$, where $a$ and $c$ are nonzero constants. Then we have $w^{(j)}+a w^{2} \neq a c^{2}$ what is all we wanted to show.

2. Some lemmas. We prove a few auxiliary results. The following notations help to simplify our presentation. By $\lambda(f)$ and $\rho(f)$ we shall always denote the upper and lower order of growth of a meromorphic function $f$; for a differential polynomial $Q[f]$ in $f$ we write $Q^{\prime}[f]$ instead of $(d / d z) Q[f]$. (Note that for an arbitrary monomial $M[f]$ in $f, M^{\prime}[f]$ can always be represented as a differential polynomial in $f$, each of whose monomials have the same degree as $M[f]$. Those differential polynomials are often called homogeneous).

Finally we shall say, following W. K. Hayman [4], that a certain property $\mathscr{P}=\mathscr{P}(r), r \in D \subseteq R$, holds "nearly everywhere" (n.e.) in $D$, if there is a subset $A \subseteq D$ of finite linear measure such that $\mathscr{P}(r)$ holds for all $r \in D \backslash A$.

LEMMA 1. Let $f$ be a nonconstant meromorphic function. If $Q[f]$ is a differential polynomial in $f$ with arbitrary meromorphic coefficients $q_{j}, 1 \leqq j \leqq n$ then

and

$$
\text { ( i ) } m(r, Q[f]) \leqq \gamma_{Q} m(r, f)+\sum_{j=1}^{n} m\left(r, q_{j}\right)+S(r, f)
$$

(ii) $\quad N(r, Q[f]) \leqq \Gamma_{Q} N(r, f)+\sum_{j=1}^{n} N\left(r, q_{j}\right)+O(1)$.

Proof. Starting with $Q[f]=\sum_{j=1}^{n} q_{j} M_{j}[f]$ (cf. (2)) we can represent $Q[f]$ as $Q[f]=\sum_{j=1}^{n} q_{j}^{*} f^{m_{j}}$ with $m_{j}:=\gamma_{M_{j}}$ and with meromorphic functions $q_{j}^{*}$ satisfying $m\left(r, q_{j}^{*}\right) \leqq m\left(r, q_{j}\right)+S(r, f), \quad j=1, \cdots, n$. This settles (i). Further, in an arbitrary $z_{0} \in C$ let $Q[f], f, q_{j}$ and $M_{j}[f]$ have poles of order $\mu, \nu, \mu_{j}$ and $\nu_{j}$ respectively (as usual a meromorphic function $f$ has poles of order zero in points $z \in C$ with $f(z) \neq \infty)$. It follows immediately, that $\mu \leqq \max \left\{\nu_{1}+\mu_{1}, \cdots, \nu_{n}+\mu_{n}\right\}$ and because of $\nu_{j} \leqq \Gamma_{M_{j}} \cdot \nu \leqq \Gamma_{Q} \cdot \nu, 1 \leqq j \leqq n$, we have

$$
\mu \leqq \Gamma_{Q} \cdot \nu+\sum_{j=1}^{n} \mu_{j}
$$

Hence $n(r, Q[f]) \leqq \Gamma_{Q} n(r, f)+\sum_{j=1}^{n} n\left(r, q_{j}\right)$ and therefore (ii) holds.

Now we use Lemma 1 to improve a result of Clunie (cf. [1], Lemmas 1 and 2).

LEMMa 2. Let $f$ be a nonconstant meromorphic function. And let $Q^{*}[f]$ and $Q[f]$ denote differential polynomials in $f$ with arbitrary meromorphic coefficients $q_{1}^{*}, \cdots, q_{n}^{*}$ and $q_{1}, \cdots, q_{\iota}$ respectively; further, let $P$ be a nonconstant polynomial of degree $p$. Then from 


$$
P(f) Q^{*}[f] \equiv Q[f]
$$

we can infer the following:

(i) if $\gamma_{Q} \leqq p$, then

$$
m\left(r, Q^{*}[f]\right) \leqq \sum_{j=1}^{n} m\left(r, q_{j}^{*}\right)+\sum_{j=1}^{\ell} m\left(r, q_{j}\right)+S(r, f)
$$

(ii) if $\Gamma_{Q} \leqq p$ we have in addition

$$
N\left(r, Q^{*}[f]\right) \leqq \sum_{j=1}^{n} N\left(r, q_{j}^{*}\right)+\sum_{j=1}^{\ell} N\left(r, q_{j}\right)+O(1) .
$$

Proof. For a proof of the first proposition see Clunie [1]. Let $n_{f}\left(r, Q^{*}[f]\right)$ denote the number of those poles of $Q^{*}[f]$ in $|z| \leqq r$ that are also poles of $f$ with the poles of $Q^{*}[f]$ being counted according to their order. Set $n^{f}\left(r, Q^{*}[f]\right):=n\left(r, Q^{*}[f]\right)-n_{f}\left(r, Q^{*}[f]\right)$ and define $N_{f}\left(r, Q^{*}[f]\right), N^{f}\left(r, Q^{*}[f]\right)$ correspondingly. We obtain immediately

$$
N^{f}\left(r, Q^{*}[f]\right) \leqq \sum_{j=1}^{n} N\left(r, q_{j}^{*}\right)+O(1) .
$$

Now we choose a point $z_{0} \in C$ where $Q^{*}[f]$ and $f$ have poles of order $\mu$ and $\nu$ respectively; denoting by $\nu_{1}, \cdots, \nu_{c}$ the orders of the poles of $q_{1}, \cdots, q_{c}$ in $z_{0}$ and considering (3) we get

$$
p \cdot \nu+\mu \leqq \Gamma_{Q} \cdot \nu+\max \left\{\nu_{1}, \cdots, \nu_{\ell}\right\}
$$

and $\Gamma_{Q} \leqq p$ yields

$$
n_{f}\left(r, Q^{*}[f]\right) \leqq \sum_{j=1}^{\ell} n\left(r, q_{j}\right) .
$$

Adding (4) this proves (ii).

We conclude by proving a lemma that will enable us to compare the orders of growth of a differential polynomial in $f$ with those of $f$.

LEMmA 3. Let $T_{1}(r), T_{2}(r)$ be real valued, nonnegative and nondecreasing functions defined for $r>r_{0}>0$ and satisfying $T_{1}(r)=$ $O\left(T_{2}(r)\right), r \rightarrow \infty$, n.e., then we have and

(i ) $\lim \sup _{r \rightarrow \infty} \log _{+}^{+} T_{1}(r) / \log r \leqq \lim \sup _{r \rightarrow \infty} \log ^{+} T_{2}(r) / \log r$

(ii) $\operatorname{lim~inf} f_{r \rightarrow \infty} \log ^{+} T_{1}(r) / \log r \leqq \lim \inf _{r \rightarrow \infty} \log ^{+} T_{2}(r) / \log r$.

This implies in particular that for meromorphic functions $f_{1}$ and $f_{2}$ with $T\left(r, f_{1}\right)=O\left(T\left(r, f_{2}\right)\right), r \rightarrow \infty$, n.e., the inequalities $\lambda\left(f_{1}\right) \leqq \lambda\left(f_{2}\right)$ and $\rho\left(f_{1}\right) \leqq \rho\left(f_{2}\right)$ hold. 
Proof. (i ) Assume without loss of generality that

$$
\lambda:=\limsup _{r \rightarrow \infty} \frac{+\log ^{\prime} T_{2}(r)}{\log r}<\infty .
$$

For arbitrary $\varepsilon>0$ there exist $R>\max \left\{r_{0}, 1\right\}, K>0$ and $D \subseteq[R, \infty)$ such that $T_{2}(r) \leqq r^{\lambda+\varepsilon}$ for $r \geqq R, T_{1}(r) \leqq K T_{2}(r)$ for $r \in[R, \infty) \backslash D$ and $m:=\operatorname{mes}(D)<\infty$. Here $m$ denotes the Lebesgue-measure of $D$. Now for $r>R+m$ and $r \in D$ one can find $r_{1}, r_{2} \notin D, R \leqq r_{1}<r<r_{2}$ and $r_{2}-r_{1} \leqq m+1$ such that $T_{1}(r) \leqq K T_{2}\left(r_{2}\right) \leqq K r_{2}^{\lambda+\varepsilon} \leqq K\left(r_{2} / r_{1}\right)^{\lambda+\varepsilon} r^{\lambda+\varepsilon} \leqq$ $C r^{\lambda+\varepsilon}$ with $C:=K(m+2)^{\lambda+\varepsilon}$, i.e., $T_{1}(r) \leqq C r^{\lambda+\varepsilon}$ for all $r>R+m$. Hence we obtain

$$
\limsup _{r \rightarrow \infty} \frac{\stackrel{+}{\log } T_{1}(r)}{\log r} \leqq \lambda+\varepsilon \quad \text { for arbitrary } \quad \varepsilon>0 ;
$$

We conclude that (i) holds.

(ii) Assume the contrary and carry on as above.

3. The proofs of Theorems 1 and 2 . With the assumptions of Theorem 1 let

$$
\Psi=f^{n} Q[f]+P[f] .
$$

By means of Lemmas 1 and 2 we see that $\Psi$ connot be constant and setting $v=\Psi^{\prime} / \Psi$ we get

$$
f^{n-1} H=v P[f]-P^{\prime}[f]
$$

where

$$
H=n f^{\prime} Q[f]+f Q^{\prime}[f]-v f Q[f] .
$$

Now Lemmas 1 and 2 show that $H \not \equiv 0$. Otherwise $\Psi^{\prime} / \Psi=$ $P^{\prime}[f] / P[f]$, i.e. $\Psi=K P[f]$ for a suitable $K \in C$ leading to $f^{n} Q[f]+$ $(1-K) P[f] \equiv 0$. However, since $\Gamma_{P} \leqq n-3$ by assumption this implies $T(r, Q[f])=S(r, f)$ by use of Lemma 2 and therefore $T\left(r, f^{n}\right) \leqq T(r, P[f])+S(r, f)$ since $Q[f] \not \equiv 0$, again by assumption. Now Lemma 1 leads to $n T(r, f) \leqq \Gamma_{P} T(r, f)+S(r, f)$ which is impossible.

Further we infer from $S(r, \Psi) \leqq S(r, f)$

$$
v P[f]-P^{\prime}[f]=T[f] \text { with } \gamma_{T} \leqq \gamma_{P}
$$

where all coefficients $t$ of the differential polynomial $T[f]$ satisfy $m(r, t)=S(r, f)$.

Therefore we can invoke Lemma 2 and (5) leads to

$$
m(r, H)=S(r, f) \text {. }
$$


It remains to be shown

$$
N(r, H) \leqq \bar{N}\left(r, \frac{1}{\Psi}\right)+S(r, f) .
$$

First choose $z_{0} \in C$ such that $H\left(z_{0}\right)=\infty$.

If $f\left(z_{0}\right)=\infty$ with order $\nu$ we get

$$
\mu \leqq \Gamma_{P} \cdot \nu+\max \left\{\nu_{1}, \cdots, \nu_{n}\right\}+1-(n-1) \cdot \nu \leqq \max \left\{\nu_{1}, \cdots, \nu_{n}\right\}
$$

where $\nu_{1}, \cdots, \nu_{n}$ and $\mu$ denote the orders of the poles of the coefficients $p_{1}, \cdots, p_{n}$ of $P[f]$ and $H$ in $z_{0}$ respectively (remember that $n \geqq 3+\Gamma_{P}$ by assumption).

Using the notations of Lemma 2 we can write this as

$$
N_{f}(r, H) \leqq \sum_{j=1}^{n} N\left(r, p_{j}\right)+S(r, f)=S(r, f) .
$$

Further, let $q_{1}, \cdots, q_{\iota}$ be the coefficients of $Q$. Then we can conclude

$$
N^{f}(r, H) \leqq 2 \sum_{j=1}^{b} N\left(r, q_{j}\right)+N^{f}(r, v)+S(r, f)
$$

and because of

$$
N^{f}(r, v) \leqq \bar{N}\left(r, \frac{1}{\Psi}\right)+\sum_{j=1}^{\ell} N\left(r, q_{j}\right)+\sum_{j=1}^{n} N\left(r, p_{j}\right)+S(r, f)
$$

we finally arrive at

$$
N^{f}(r, H) \leqq \bar{N}\left(r, \frac{1}{\Psi}\right)+S(r, f) .
$$

Now (10) and (11) together prove that (9) is valid.

Noting that $H \not \equiv 0$ one infers from (3), (8) and (9) using

$$
T\left(r, f^{n-1}\right) \leqq T\left(r, v P[f]-P^{\prime}[f]\right)+T(r, H)+S(r, f)
$$

and

$$
N\left(r, v P[f]-P^{\prime}[f]\right) \leqq \Gamma_{P} N(r, f)+\bar{N}(r, f)+\bar{N}\left(r, \frac{1}{\Psi}\right)+S(r, f)
$$

the inequality

$$
T\left(r, f^{n-1}\right) \leqq \Gamma_{P} T(r, f)+\bar{N}(r, f)+2 \bar{N}\left(r, \frac{1}{\Psi}\right)+S(r, f) .
$$

Here use was made of Lemma 1 (i). Keeping in mind however that $\Gamma_{P} \leqq n-3$ we get

$$
T(r, f)=O\left(\bar{N}\left(r, \frac{1}{\Psi}\right)\right), \quad r \longrightarrow \infty, \quad \text { n.e. }
$$

The rest is easy. 
First one clearly sees that the assumption $\bar{N}(r, 1 / \Psi)=S(r, f)$ leads to a contradiction, hence zero cannot be a Picard exceptional value of $\Psi$ and we have

$$
\limsup _{r \rightarrow \infty} \frac{\bar{N}(r, 1 / \Psi)}{T(r, \Psi)}>0
$$

Applying Lemma 3 to equation (12) we get

$$
\lambda(f) \leqq \limsup _{r \rightarrow \infty} \frac{\log ^{+} \bar{N}(r, 1 / \Psi)}{\log r}=: \lambda,
$$

and observing $\lambda \leqq \lambda(\Psi) \leqq \lambda(f)$ we see, that zero cannot be a Borel exceptional value of $\Psi$ either. This completes the proof of Theorem 1.

REMARK. Using (12) and Lemma 3 we obtain $\lambda(f)=\lambda(\Psi)$ and $\rho(f)=\rho(\Psi)$ under the stated assumptions.

The proof of Theorem 2 is now easily accomplished. Assume $N(r, f)=S(r, f)$ then due to

$$
T(r, P[f]) \leqq(n-2) T(r, f)+S(r, f) \text { and } N(r, Q[f])=S(r, f)
$$

(cf. Lemmas 1 and 2, (5) and (6)) one gets just as in the proof of Theorem 1

$$
\Psi \not \equiv c, \quad H \not \equiv 0, \quad T(r, H) \leqq \bar{N}\left(r, \frac{1}{\Psi}\right)+S(r, f)
$$

where analogous notation is used. And from

$$
f^{n-1} H=\frac{\Psi^{\prime}}{\Psi} P[f]-P^{\prime}[f]
$$

we infer that

$$
(n-1) T(r, f) \leqq(n-2) T(r, f)+2 \bar{N}\left(r, \frac{1}{\Psi}\right)+S(r, f)
$$

and therefore

$$
T(r, f)=O\left(\bar{N}\left(r, \frac{1}{\Psi}\right)\right), \quad r \longrightarrow \infty, \text { n.e. },
$$

holds again.

The statements of Theorem 2 are now obvious.

REMARK. As above, $\Psi$ and $f$ have again the same upper and lower orders of growth. 
4. Acknowledgement. I am indebted to Mrs. Kern, who did the typing and to Mr. and Mrs. B. Kawohl for valuable comments.

\section{REFERENCES}

1. J. Clunie, On integral and meromorphic functions, J. London Math. Soc., 37, (1962), $17-27$.

2. - On a result of Hayman, J. London Math. Soc., 47 (1967), 389-392.

3. W. K. Hayman, Meromorphic Functions, Oxford, Clarendon Press 1975.

4. - Picard values of meromorphic functions and their derivatives, Ann. of Math., II. Ser. 70 (1959), 9-42.

5. E. Mues, Über die Nullstellen homogener Differential polynome, manuscripta math. 23 (1978), 325-341.

6. ——Über ein Problem von Hayman, Math. Z., 164 (1979), 239-259.

7. —, Zur Wertverteilung von Differentialpolynomen, Arch. Math. 32 (1979), $55-67$.

8. R. Nevanlinna, Eindeutige Analytische Funktionen, Berlin, Heidelberg, New York: Springer 1974.

9. L. R. Sons, Deficiencies of monomials, Math. Z. 111 (1969), 53-68.

10. H. Wittich, Einige Eigenschaften der Lösungen von $w^{\prime}=a(z)+b(z) w+c(z) w^{2}$, Arch. Math., 5 (1954), 226-232.

11. - Neuere Untersuchungen über eindeutige analytische Funktionen, Berlin, Göttingen, Heidelberg: Springer 1955.

12. C. C. Yang, Applications of the Tumura-Clunie Theorem, Trans. Amer. Math. Soc., 151 (1970), 659-662.

13. - On deficiencies of differential polynomials, Math. Z., 116 (1970), 197-204.

14. On deficiencies of differential polynomials II, Math. Z., 125 (1972), $107-112$.

Received December 1, 1980 and in revised form March 27, 1981.

ABT. FÜr MATHEMATIK VII

DER UNIVERSITÄT ULM

OBERER ESELSBERG

D-7900 ULM

Federal Republic of Germany 


\title{
PACIFIC JOURNAL OF MATHEMATICS
}

\section{EDITORS}

\author{
DONALD BABBITT (Managing Editor) \\ University of California \\ Los Angeles, CA 90024 \\ Hugo RossI \\ University of Utah \\ Salt Lake City, UT 84112 \\ C. C. Moore and ANDrew OGG \\ University of California \\ Berkeley, CA 94720
}

\section{J. DugundjI}

Department of Mathematics

University of Southern California

Los Angeles, CA 90007

R. FinN and J. Milgram

Stanford University

Stanford, CA 94305

\section{ASSOCIATE EDITORS}
R. ARENS
E. F. BeCKENBACH
B. H. NeUMANN
F. WOLF
K. YoshidA

\section{SUPPORTING INSTITUTIONS}

UNIVERSITY OF ARIZONA

UNIVERSITY OF BRITISH COLUMBIA

CALIFORNIA INSTITUTE OF TECHNOLOGY

UNIVERSITY OF CALIFORNIA

MONTANA STATE UNIVERSITY

UNIVERSITY OF NEVADA, RENO

NEW MEXICO STATE UNIVERSITY

OREGON STATE UNIVERSITY

\author{
UNIVERSITY OF OREGON \\ UNIVERSITY OF SOUTHERN CALIFORNIA \\ STANFORD UNIVERSITY \\ UNIVERSITY OF HAWAII \\ UNIVERSITY OF TOKYO \\ UNIVERSITY OF UTAH \\ WASHINGTON STATE UNIVERSITY \\ UNIVERSITY OF WASHINGTON
}

The Supporting Institutions listed above contribute to the cost of publication of this Journal, but they are not owners or publishers and have no responsibility for its content or policies.

Mathematical papers intended for publication in the Pacific Journal of Mathematics should be in typed form or offset-reproduced, (not dittoed), double spaced with large margins. Please do not use built up fractions in the text of the manuscript. However, you may use them in the displayed equations. Underline Greek letters in red, German in green, and script in blue. The first paragraph or two must be capable of being used separately as a synopsis of the entire paper. Please propose a heading for the odd numbered pages of less than 35 characters. Manuscripts, in triplicate, may be sent to any one of the editors. Please classify according to the scheme of Math. Reviews, Index to Vol. 39. Supply name and address of author to whom proofs should be sent. All other communications should be addressed to the managing editor, or Elaine Barth, University of California, Los Angeles, California, 90024.

50 reprints to each author are provided free for each article, only if page charges have been substantially paid. Additional copies may be obtained at cost in multiples of 50 .

The Pacific Journal of Mathematics is issued monthly as of January 1966. Regular subscription rate: $\$ 102.00$ a year (6 Vols., 12 issues). Special rate: $\$ 51.00$ a year to individual members of supporting institutions.

Subscriptions, orders for numbers issued in the last three calendar years, and changes of address shoud be sent to Pacific Journal of Mathematics, P.O. Box 969, Carmel Valley, CA 93924, U.S.A. Old back numbers obtainable from Kraus Periodicals Co., Route 100, Millwood, NY 10546.

PUBLISHED BY PACIFIC JOURNAL OF MATHEMATICS, A NON-PROFIT CORPORATION

Printed at Kokusai Bunken Insatsusha (International Academic Printing Co., Ltd.). 8-8, 3-chome, Takadanobaba, Shinjuku-ku, Tokyo 160, Japan. 


\section{Pacific Journal of Mathematics}

\section{Vol. 98, No. 1 \\ March, 1982}

Humberto Raul Alagia, Cartan subalgebras of Banach-Lie algebras of

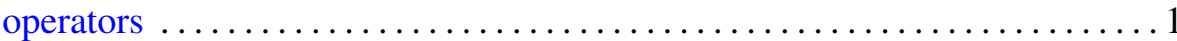

Tom M. (Mike) Apostol and Thiennu H. Vu, Elementary proofs of

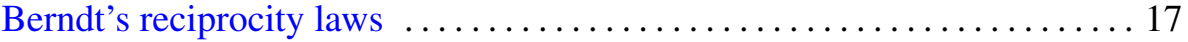

James Robert Boone, A note on linearly ordered net spaces $\ldots \ldots \ldots \ldots . \ldots 25$

Miriam Cohen, A Morita context related to finite automorphism groups of

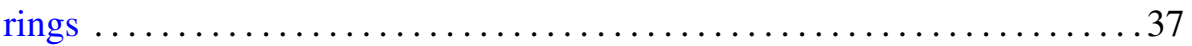

Willibald Doeringer, Exceptional values of differential polynomials . . . . . . 55

Alan Stewart Dow and Ortwin Joachim Martin Forster, Absolute

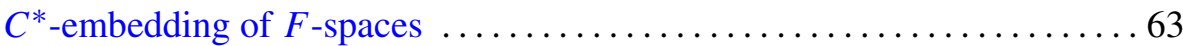

Patrick Hudson Flinn, A characterization of $M$-ideals in $B\left(l_{p}\right)$ for

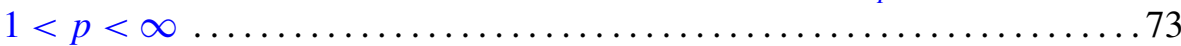

Jack Emile Girolo, Approximating compact sets in normed linear spaces . . . 81

Antonio Granata, A geometric characterization of $n$th order convex

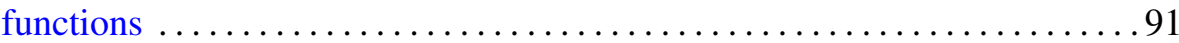

Kenneth Richard Johnson, A reciprocity law for Ramanujan sums . . . . . . .99

Grigori Abramovich Kolesnik, On the order of $\zeta\left(\frac{1}{2}+i t\right)$ and $\Delta(R) \ldots \ldots 107$

Daniel Joseph Madden and William Yslas Vélez, Polynomials that

represent quadratic residues at primitive roots $\ldots \ldots \ldots \ldots \ldots \ldots \ldots 123$

Ernest A. Michael, On maps related to $\sigma$-locally finite and $\sigma$-discrete

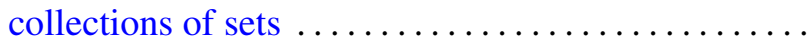

Jean-Pierre Rosay, Un exemple d'ouvert borné de $\mathbf{C}^{3}$ “taut" mais non

hyperbolique complet

Roger Sherwood Schlafly, Universal connections: the local problem

Russel A. Smucker, Quasidiagonal weighted shifts .....

Eduardo Daniel Sontag, Remarks on piecewise-linear algebra . .

Jan Søreng, Symmetric shift registers. II

H. M. (Hari Mohan) Srivastava, Some biorthogonal polynomials suggested

by the Laguerre polynomials 